\title{
A Cross-Sectional Survey of Factors Influencing Choice of Medical Care Among Ill Patients Suffering from Chronic Diseases in Ebonyi State, Nigeria
}

\author{
Uchechukwu A. Ezugwu ${ }^{1}$, Jude N. Nwafor ${ }^{2}$, Ignatius O. Nwimo ${ }^{3}$, Nwamaka A. Elom ${ }^{3}$, Cajetan I. Ilo ${ }^{3}$, \\ Lazarus E. Ezugwu ${ }^{4} \&$ Rita N. Ejide ${ }^{3}$ \\ ${ }^{1}$ Department of Medical Rehabilitation, University of Nigeria, Nsukka, Nigeria \\ ${ }^{2}$ Department of Physical and Health Education, Ebonyi State College of Education, Ikwo Abakaliki, Nigeria \\ ${ }^{3}$ Department of Human Kinetics and Health Education, Ebonyi State University, Abakaliki, Nigeria \\ ${ }^{4}$ School of Health, Orji River, Enugu State, Nigeria \\ Correspondence: Ignatius O. Nwimo, Department of Human Kinetics and Health Education, Ebonyi State \\ University, Abakaliki, Nigeria. Tel: 234-803-554-3617. E-mail: ignatius.nwimo@ebsu.edu.ng
}

Received: May 29, 2020 Accepted: June 20, 2020 Online Published: July 6, 2020

doi:10.5539/gjhs.v12n9p60

URL: https://doi.org/10.5539/gjhs.v12n9p60

\begin{abstract}
The cross-sectional survey research design was used to the study the factors influencing choice of medical care among ill patients suffering from chronic diseases in Ebonyi State. The sample of the study comprised 325 in-patients with selected chronic diseases such as diabetics' mellitus, cardiac and renal diseases who were undergoing treatment at the Federal Teaching Hospital (FETHA 1) Abakaliki. The instrument used for data collection was a 26-item questionnaire developed by the researchers. Data collected were analyzed using percentages in order to describe the data and chi-square $\left(\chi^{2}\right)$ statistic in order to establish whether there was any significant association between the independent variables of gender and level education attained and the dependent variables, that is, the factors influencing choice of medical care among chronic diseases patients. The results of the study showed that the association between gender and factors influencing choice of medical care is not significant except for culture, employer and strong hope of cure $(p<0.05)$. Secondly, the association between level of education attained by patients and factors influencing choice of medical care is significant except for finance, access to hospital, relationship with medical personnel and adequacy of hospital facilities ( $\mathrm{p}>$ 0.05). The need for chronic diseases clinics and hospitals for prompt treatment of chronic diseases patients is advocated.
\end{abstract}

Keywords: choice of medical care, chronic diseases, patients, Ebonyi State

\section{Introduction}

Illness has been conceptualized in many ways. For example, Abanobi and Ewuzie (2000) perceived illness as human response to disease process or the perception by an individual that he or she has some form of impairment. Similarly, British Medical Association (2002) noted that illness is the perception by a person that he or she is not well. The British Medical Association added that illness is a subjective sensation experienced by an individual who has some feeling of deviation from normal health. This subjective sensation, according to Reiners, Sturm, Lisette, Bouw, Eveline and Wouters (2019), may have some psychological undertone. World Health Organization (2018a) perceived illness as a disease of the body and mind or a condition of being ill.

A close observation of the definitions of illness presented above could show that they are similar in that they see illness as human response to disease process which is capable of making the ill individual exhibit a particular behavior in reaction to his or her condition.

According to Uzama, Underwood, Atkinson and Thackrah (2012), disease episode could be acute or chronic. However, Reiners, Sturm, Lisette, Bouw, Eveline and Wouters (2019) described chronic disease as an illness or medical condition that lasts over a long period and sometimes causes a long-term change in the body. On their own part, Tipping and Segall (2014) perceived chronic diseases to mean those diseases that develop over time and require more than six or more months to heal, and some may persist indefinitely. They gave examples of 
chronic diseases to include tuberculosis, asthma, diabetes, hypertension and other cardiac problems, and kidney or renal diseases.

In the context of the present study, chronic diseases are described as those diseases that last over a long period and sometimes persist indefinitely. Therefore the behavior of the patient experiencing any one chronic disease, such as diabetes, cardiac problems, and kidney or renal diseases identified by Tipping and Segall (2014) above were used in order to determine the factors influencing choice of medical care among ill patients suffering from chronic diseases in Ebonyi State.

The knowledge of care seeking behavior during illness especially in terms of how ill people feel they are and their choice of medical care is very pertinent. This is of much importance in rendering care to the patients. Studies (Erinosho, 1979; Woods, 2003; Zhu, Liu, Che, \& Chen, 2018; Biraguma, Mutimura, \& Frantz, 2019) have shown that individuals react to illness in various ways. What one individual may identify as illness may not be regarded as illness by another individual. Similarly, what one society may regard as illness may be seen by another society as normal. For instance, Abanobi (2014) observed that in developing countries like Nigeria, people with headache or fever go about their normal duties and are not regarded as sick while in developed countries like America or Britain, people with such symptoms as headache, might interpret the symptoms as serious warning signs of illness. This interpretation may affect the individual's behavior towards the condition. Studies (Petersen, van den Berg, Janssens, \& Van den Bergh, 2010; Riegel, Jaarsma, \& Strömberg, 2012; Tipping \& Segall, 2014) demonstrated that choice or decision to engage or seek a particular medical channel is influenced by a variety of socio-demographic variables such as sex and level of education attained. These socio-demographic variables are the variables that were examined in this study in order to determine the influence the variables exert on the illness behavior of the patients with the selected chronic diseases in Abakaliki, Ebonyi State.

A patient, according to Sidhu (2012), is a person receiving treatment from a doctor and or hospital. For Levin and Hanson (2020) a patient is an individual whose incapacity disturbs performance of the social roles he or she is normally charged with and exposes him or her to the attention of medical personnel. The patient described above could be one suffering any chronic disease including, diabetes, cardiac and renal diseases. In the context of this study therefore, a patient is perceived as one who is suffering any of the chronic diseases indicated above and the disease exposes him or her to the attention of a medical doctor.

One of the most outstanding challenges to public health is the problem of the chronically ill. Chronic illness affects almost every family and it has been estimated that about 25 million persons, or over one-sixth of the population of the developing world, have one chronic disease or the other. It is estimated that over 7 million of these chronic ill persons have an appreciable disability from their illness and at least a million and a half are invalids. The above submission concerned chronic disease patients in developing countries, including Nigeria. Important in the chronic illnesses are arteriosclerosis, high blood pressure, mental disease, arthritis, heart and kidney diseases, cancer, tuberculosis, diabetes, and asthma (Fong, Bargman, \& Chan, 2007; Nugent, 2008).

Chronic diseases, also known as non-communicable diseases, constitute a significant challenge for healthcare. As reported by the WHO, each year $71 \%$ of deaths are due to chronic diseases (World Health Organization, 2018b). Moreover, the number of people with chronic diseases is steadily growing when considering the increase in the number of older persons. At present, Europe has the highest percentage of people aged 60 or over (United Nations, Department of Economic and Social Affairs, 2015). In other parts of the world, including Africa, rapid ageing will occur, such that a quarter of their populations will be older than 60 (United Nations, Department of Economic and Social Affairs, 2015). In addition, the economic burden of chronic diseases and the workload for health caregivers will increase accordingly (Settumba, Sweeney, Seeley, Biraro, Mutungi, Munderi, Grosskurth, \& Vassall, 2015; Gheorghe, Griffiths, Murphy, Legido-Quigley, Lamptey, \& Perel, 2018). The most prevalent chronic diseases are cancer, chronic respiratory disease, cardiovascular disease, and diabetes. All these diseases are to some extent related to behavioral risk factors such as tobacco use, unhealthy diet, lack of physical activity, and use of alcohol (World Health Organization, 2018b). Thus, patients need to take responsibility in order to actively change their behavior and manage their chronic illness. This concept, which is known as self-management, is currently widely adopted to improve health outcomes and quality of life among chronically ill patients (Talboom-Kamp, Verdijk, Kasteleyn, Numans, \& Chavannes, 2018).

Since chronic disease causes nearly a million deaths each year and causes the loss of almost a billion days of productive activity, action against this group of diseases is most important and this action might probably be initiated when the factors influencing their choice of medical care during illness is determined. It is the expectation of every society that patients should seek care and get well. Variations exist in how individuals 
choose to seek medical care when they become ill. These variations in care seeking might result in individual's use and non-use of health care services, especially among the chronically ill patients.

The researchers have observed that chronic disease patients in Ebonyi State appear to lack the proper direction. Some embark on self medication, others prefer native healers and faith healing for reasons of affordability, some who have the courage to consult doctors in hospitals do that when it is already too late thus exposing themselves to deaths which ordinarily would have been prevented. The above scenario prompted the researchers to explore the factors influencing choice of medical care among patients of chronic diseases in Ebonyi State.

A report (Dulla, Daka, \& Wakgari, 2017) indicated that majority of rural dwellers utilized the services of assorted traditional healers before and even after seeking care from modern health care and a good number of the rural sick engaged the services of patent medicine dealers. According to the report this behavior sometimes resulted to irreversible complication or death that might have ordinarily been avoided. Certain factors may be responsible for the rural dwellers described above utilizing traditional healer before and after seeking modern health care. The situation described above concerned the sick in rural settings in Northern Nigeria and the situation in Ebonyi State may not be different especially among the chronically ill. Regrettably, the situation with regard to the chronically ill, probably, has not been explored in Ebonyi State in the recent times.

Unlike in developed countries, research on factors affecting patient's choice of health care provider in Nigeria has not been fully explored. It is not very clear what influences the chronically ill patient's choice of one or the other within a health system with many health care providing facilities. The behavior of the patients which is made evident by their choice of medical care provider may also give an insight into how these health facilities can improve on their service delivery, improve client satisfaction and by extension ensure a healthier population (Uchendu, Ilesanmi, \& Olumide, 2013).

The problem of this study can therefore be stated in a question form, thus: what are the factors influencing choice of medical care among ill patients suffering from chronic diseases in Ebonyi State? To provide answer to this question, the present study therefore was carried out to investigate the factors influencing choice of medical care among ill patients suffering from chronic diseases in Ebonyi State.

\section{Material and Methods}

\subsection{Design}

The cross-sectional survey research design was used for the study. The population of the study comprised all patients with chronic diseases such as diabetics' mellitus, cardiac and renal diseases who were undergoing treatment at the Federal teaching hospital (FETHA 1) Abakaliki. They included both out-patients in the special clinics of the hospital and those on admission during the period of the study. According to the medical record unit of the hospital as at February 2020, the number of patients with the selected chronic diseases who were receiving treatment in the hospital before COVID-19 lockdown was 754 patients. Out of this number, 325 were in-patients while 429 were out-patients receiving treatment from their homes. However, only in-patients were included and used to collect data for this study. Out-patients were excluded from the study because most of them could not be reached as a result of variations in the days of appointment.

\subsection{Ethics Statement}

Ethical approval was granted by Ebonyi University Medical School Research Ethics Committee and the Alex Ekwueme University Federal Teaching Hospital (FETHA). Each participant agreed orally to take part in the study.

\subsection{Instrument}

The instrument used in this study was a 26-item Chronic Diseases Patients' Choice of Care Questionnaire (CDPCCQ) developed by the researcher. Items in the questionnaire were gathered from literature on chronic diseases. The questionnaire consisted of two sections; sections A and B. Section A contained four items on personal data of respondents. Section B contained 22 items that elicited information on factors influencing the patients' choice of care. Five experts from one institution of higher learning in Ebonyi State were used for validating the CDPCCQ. Fifteen chronic diseases patients of both genders who were undergoing treatment in one hospital in Enugu State were used for test of reliability. The data yielded a split-half reliability coefficient of 0.94 . The reliability coefficient was higher than Ogbazi and Okpala's (2014) criteria of 0.60 acceptable for good instruments.

\subsection{Data Analysis}

The returned copies of the questionnaire were cross-checked for completeness of responses. Copies that had 
complete responses were used for data analysis. All the research questions were answered using percentages, because of the need for nominal data while the hypotheses were tested using the chi-square $\left(\chi^{2}\right)$ statistic. The hypotheses were tested at alpha level of 0.05. All data analysis was done with the use of Statistical Package for Social Sciences (SPSS) version 23.

\section{Results}

Table 1. Factors Influencing choice of medical care

\begin{tabular}{|c|c|c|c|}
\hline \multirow{2}{*}{$\mathbf{S} / \mathbf{N}$} & \multirow{2}{*}{ Variables } & \multicolumn{2}{|c|}{ Responses } \\
\hline & & f & $\%$ \\
\hline 1. & Fear & 222 & 68.3 \\
\hline 2. & Frustration & 212 & 65.2 \\
\hline 3. & Past experience & 153 & 47.1 \\
\hline 4. & Personal motivation & 236 & 72.6 \\
\hline 5. & Culture & 208 & 64.0 \\
\hline 6. & Religion & 228 & 70.2 \\
\hline 7. & Finance & 198 & 60.9 \\
\hline 8. & Employer & 197 & 60.6 \\
\hline 9. & Spouse & 224 & 68.9 \\
\hline 10. & Children & 187 & 57.5 \\
\hline 11. & Friends & 259 & 79.7 \\
\hline 12. & Other relatives & 215 & 66.2 \\
\hline 13. & Knowledge of disease & 106 & 32.2 \\
\hline 14. & Degree of severity of illness & 236 & 72.3 \\
\hline 15. & Strong hope of cure & 224 & 68.9 \\
\hline 16. & Access to hospital & 183 & 56.3 \\
\hline 17. & Affordability of hospital expense & 251 & 77.2 \\
\hline 18. & Relationship with medical personnel & 219 & 67.4 \\
\hline 19. & Adequacy of hospital in terms of staffing & 281 & 86.5 \\
\hline 20. & Adequacy of hospital in terms of facilities & 200 & 61.5 \\
\hline 21. & Feeling of worth & 211 & 64.9 \\
\hline 22. & Feeling that the illness has no cure & 124 & 38.2 \\
\hline
\end{tabular}

Table 1 shows that the factors that influence choice of medical care among respondents include adequacy of staff in the hospital, friends, and ability to afford hospital expenses, severity of illness, religion, spouse and strength of hope. Other factors include fear the disease instilled in them, relationship with medical personnel who may have advised them, other relatives, feeling of worth and their culture, among other factors. 
Table 2. Factors influencing choice of Medical care by male and female respondents

\begin{tabular}{|c|c|c|c|c|c|}
\hline \multirow{2}{*}{$\mathbf{S} / \mathbf{N}$} & \multirow{2}{*}{ Variables } & \multicolumn{2}{|c|}{ Gender } & \multirow{2}{*}{$\chi^{2}$-value } & \multirow{2}{*}{ p-value } \\
\hline & & Male $(n=168)$ & Female $(n=157)$ & & \\
\hline 1. & Fear & 63.6 & 73.2 & 3.425 & 0.064 \\
\hline 2. & Frustration & 65.4 & 64.9 & 0.009 & 0.923 \\
\hline 3. & Past experience & 48.8 & 45.2 & 0.419 & 0.517 \\
\hline 4. & Personal motivation & 69.0 & 76.4 & 2.226 & 0.136 \\
\hline 5. & Culture & 69.6 & 57.9 & $4.806^{*}$ & 0.028 \\
\hline 6. & Religion & 73.2 & 66.8 & 1.556 & 0.212 \\
\hline 7. & Finance & 59.5 & 62.4 & 0.286 & 0.593 \\
\hline 8. & Employer & 67.8 & 52.8 & $7.640^{*}$ & 0.006 \\
\hline 9. & Spouse & 75.5 & 74.5 & 0.050 & 0.823 \\
\hline 10. & Children & 60.7 & 54.1 & 1.436 & 0.231 \\
\hline 11. & Friends & 82.1 & 77.0 & 1.290 & 0.256 \\
\hline 12. & Other relatives & 64.2 & 68.1 & 0.542 & 0.462 \\
\hline 13. & Knowledge of disease & 29.1 & 36.3 & 1.882 & 0.170 \\
\hline 14. & Degree of severity of illness & 70.2 & 74.5 & 0.744 & 0.388 \\
\hline 15. & Strong hope of cure & 73.8 & 63.6 & $3.877^{*}$ & 0.049 \\
\hline 16. & Access to hospital & 54.1 & 58.5 & 0.648 & 0.421 \\
\hline 17. & Affordability of hospital expense & 75.5 & 78.9 & 0.529 & 0.467 \\
\hline 18. & Relationship with medical personnel & 70.8 & 63.6 & 1.882 & 0.170 \\
\hline 19. & Adequacy of hospital in terms of staffing & 86.9 & 85.9 & 0.058 & 0.809 \\
\hline 20. & Adequacy of hospital in terms of facilities & 61.9 & 61.1 & 0.020 & 0.888 \\
\hline 21. & Feeling of worth & 61.9 & $68 . .1$ & 1.391 & 0.238 \\
\hline 22. & Feeling that the illness has no cure & 40.4 & 36.6 & 0.795 & 0.373 \\
\hline
\end{tabular}

$* p<0.05$

Table 2 above presents data on factors influencing choice of medical care by male and female respondents. As can be seen in the table, $63.6 \%$ of male respondents and $73.2 \%$ of female respondents are influenced by fear; $65.4 \%$ of the males and $64.9 \%$ of the females are influenced by frustration presented by the illness. On the other hand, $69.0 \%$ of male respondents and $76.4 \%$ of the females are influenced by personal motivation; $69.6 \%$ of males and $57.9 \%$ of females are influenced by culture. Furthermore, $66.8 \%$ of males and $73.2 \%$ of females are influenced by religion and while $54.1 \%$ of males and $58.5 \%$ of females are influenced by accessibility of the hospital, $75.5 \%$ males and $78.9 \%$ females are influenced by affordability of hospital expenses. When chi-square is run, it is observed that the association between gender and factors influencing choice of medical care by male and female respondents is not significant except for culture, employer and strong hope of cure $(p<0.05)$. 
Table 3. Factors Influencing Choice of Medical Care according to Level of Education of Respondents

\begin{tabular}{|c|c|c|c|c|c|c|c|}
\hline \multirow[b]{2}{*}{$\mathrm{S} / \mathrm{N}$} & \multirow[b]{2}{*}{ Variables } & \multicolumn{4}{|c|}{ Level of Education Attained } & \multirow[b]{2}{*}{$\chi^{2}$-value } & \multirow[b]{2}{*}{ p-value } \\
\hline & & $\begin{array}{l}\text { NFE } \\
(n=71)\end{array}$ & $\begin{array}{l}\text { PE } \\
\quad(n=52)\end{array}$ & $\begin{array}{l}\text { SE } \\
(n=70)\end{array}$ & $\begin{array}{l}\text { TE } \\
(n=132)\end{array}$ & & \\
\hline 1. & Fear & 59.1 & 82.6 & 78.5 & 62.1 & $13.458^{*}$ & 0.004 \\
\hline 2. & Frustration & 81.6 & 75.0 & 71.4 & 49.2 & $26.732 *$ & 0.000 \\
\hline 3. & Past experience & 47.8 & 32.6 & 30.0 & 61.3 & $23.345^{*}$ & 0.000 \\
\hline 4. & Personal motivation & 60.5 & 71.1 & 90.0 & 70.4 & $16.191^{*}$ & 0.001 \\
\hline 5. & Culture & 64.7 & 86.5 & 68.5 & 52.2 & $19.998^{*}$ & 0.000 \\
\hline 6. & Religion & 690 & 80.7 & 80.0 & 61.3 & $10.955^{*}$ & 0.012 \\
\hline 7. & Finance & 53.5 & 59.6 & 62.8 & 64.3 & 2.449 & 0.485 \\
\hline 8. & Employer & 60.5 & 71.1 & 75.7 & 48.4 & $17.240^{*}$ & 0.001 \\
\hline 9. & Spouse & 70.4 & 86.5 & 82.8 & 68.9 & $9.395^{*}$ & 0.024 \\
\hline 10. & Children & 64.7 & 59.6 & 64.2 & 49.2 & 6.642 & 0.084 \\
\hline 11. & Friends & 78.8 & 90.3 & 84.2 & 73.4 & $7.758^{*}$ & 0.051 \\
\hline 12. & Other relatives & 63.3 & 75.0 & 75.7 & 59.0 & $7.860^{*}$ & 0.049 \\
\hline 13. & Knowledge of disease & 14.0 & 23.0 & 24.2 & 50.7 & $35.951^{*}$ & 0.000 \\
\hline 14. & Degree of severity of illness & 69.0 & 80.7 & 84.2 & 64.3 & $11.388^{*}$ & 0.010 \\
\hline 15. & Strong hope of cure & 67.6 & 53.8 & 67.1 & 76.5 & $9.232 *$ & 0.026 \\
\hline 16. & Access to hospital & 50.7 & 57.6 & 55.7 & 59.0 & 1.372 & 0.712 \\
\hline 17. & Affordability of hospital expense & 80.2 & 90.3 & 82.8 & 67.4 & $13.971^{*}$ & 0.003 \\
\hline 18. & Relationship with medical personnel & 63.3 & 65.3 & 65.7 & 71.2 & 1.581 & 0.664 \\
\hline 19. & Adequacy of hospital in terms of staffing & 87.3 & 86.5 & 97.1 & 80.3 & $11.145^{*}$ & 0.011 \\
\hline 20. & Adequacy of hospital in terms of facilities & 61.9 & 57.7 & 54.2 & 66.6 & 3.353 & 0.340 \\
\hline 21. & Feeling of worth & 53.5 & 59.6 & 80.0 & 65.1 & $11.687^{*}$ & 0.009 \\
\hline 22. & Feeling that the illness has no cure & 56.3 & 42.3 & 25.7 & 33.3 & $16.220^{*}$ & 0.001 \\
\hline
\end{tabular}

Table 3 presents data on factors influencing choice of medical care according to level of education of the respondents. The table shows that respondents with primary education (PE) are influenced by fear $(82.6 \%)$, frustration (75\%), past experience (32.6\%), personal motivation $(71.1 \%)$, culture $(86.5 \%)$ and religion $(80.7 \%)$. Other factors are finance $(59.6 \%)$, employer $(71.1 \%)$, spouse $(86.5 \%)$, friends $(90.3 \%)$, other relatives $(75 \%)$ and affordability of hospital expense $(90.3 \%)$. On the other hand respondents with secondary level of education (SE) are influenced by fear $(78.5 \%)$, frustration $(71.4 \%)$, personal motivation $(90 \%)$, culture $(68.5 \%)$, religion $(80 \%)$, finance $(62.8 \%)$, employer $(75.7 \%)$, spouse $(82.8 \%)$ children $(64.2 \%)$, friends $(84.2 \%)$, and other relatives $(75.7 \%)$ and while $84.2 \%$ respondents are influenced by severity of illness, $97.1 \%$ are influenced by adequacy hospital staff.

Among those with tertiary education (TE), $62.1 \%$ are influenced by fear, $49.2 \%$ by frustration, $61.3 \%$ by past experience, $70.4 \%$ by personal motivation, $52.2 \%$ by culture, $61.3 \%$ by religion, $64.3 \%$ by finance, $48.4 \%$ by employers, $68.9 \%$ by spouse, $73.4 \%$ by friends, $76.5 \%$ by strong hope of cure and $80.3 \%$ staff of hospital. Furthermore, among those with non-formal education (NFE), 59.1\% are influenced by fear, $81.6 \%$ by frustration, $60.5 \%$ by personal motivation, $64.7 \%$ by culture-induced, $69 \%$ religion, and $70.4 \%$ by spouse $70.4 \%, 66.7 \%$ by children, $78.8 \%$ by friends, $80.2 \%$ by affordability of hospital expenses and $63.3 \%$ by relationship with medical personnel. When chi-square is run, it is observed that the association between level of education attained by respondents and factors influencing choice of medical care is significant except for finance, access to hospital, relationship with medical personnel and adequacy of hospital in terms of facilities $(p>0.05)$. 


\section{Discussion}

Results in Table 1 showed the factors that influenced the choice of medical care of the chronically illness patients. The results showed that $86.5 \%$ of the patients were influenced by the quality of staff in the hospital they chose. Experience show that human beings go for wherever best they can find especially as it affects their health matters. This could explain why out of the two tertiary health care facilities in Ebonyi State, one seems to be enjoying higher patronage than the other for reasons of quantitative staffing and their numerical adequacy. The results also showed that $72.3 \%$ of the respondents were influenced by the degree of severity of the illness. This finding is indeed expected owing to the value every human being attaches to his or her life. Any condition that is a threat to life had always been known to put the individual concerned on his or her toes in a bid to ensure survival.

These findings support earlier observation (Musinguzi, Anthierens, Nuwaha, Geertruyden, Wanyenze, \& Bastiaens, 2018) that what an individual regards as a serious illness may be seen as normal by another individual. Abanobi (2014) had also observed that in most developing countries like Nigeria, people with headache or fever go about their normal duties and are not regarded as sick until it becomes sever; the implication of this is that people of the area do not go for treatment early enough except when the illness becomes severe. This is a risky behavior that could expose the individual concerned to irreversible complication of his aliment or even death The results further showed that $38.2 \%$ of the respondents were led into complacency by the feeling that the illness has no cure.

This finding is indeed very strange as it disagrees sharply with the assertion that every society expects her sick patients to get well. The patients who have the feeling that their ailment has no cure may consider going for treatment a waste of resources that could be spend on more useful things. They then relax and be waiting to die. This behavior is very dangerous because if you sit and wait to die, you may not wait too long (Nwafor, 2011; Desai, Kandavel, \& Chaturvedi, 2019).

Results of the study on Table 2 showed that $86.9 \%$ of the male respondents were influenced by adequacy of hospital in terms of staffing in choice of facility while the same applied to $85.9 \%$ of the female respondents. These findings are not surprising because it is personnel that make an institution. The findings also agree with the views of the Federal Ministry of Health (2019) who stated that the life wire of any institution especially health institutions is the quality of her personnel. According to her it determines its growth and societal acceptance.

Results of the study on Table 3 indicates that $90.3 \%$ of respondents with primary education were influenced by their friends, friends also influenced $84.2 \%$ of the group with secondary education and $73.4 \%$ of the respondents with tertiary level of education were also influenced by friends. Similarly, friends influenced the choice of medical care of $78.8 \%$ respondents with non-formal education. These findings support the earlier observation (Serap \& Bayram, 2015; Al-Hajje, Awada, Rachidi, Zein, Bawab, El-Hajj, Bou Zeid, Yassine, \& Salameh, 2015; Desai, Kandavel, \& Chaturvedi, 2019) on the high influence of significant others in the life of people in the society with chronic diseases patients inclusive.

\section{Conclusion and Recommendation}

From the findings of the study, it is safe to conclude that poverty and high cost of medical services in Ebonyi State in particular and the country in general is a serious barrier to access to health care. The same factor tends to encourage medical quackery and fake drug vending both in the state and the country at large. Special clinics for the treatment of chronic diseases patients should be established in public hospitals and their charge subsidized to encourage patients to freely go for prompt treatment willingly when need arises.

\section{Funding}

The authors received no financial support for the research, authorship, and/or publication of this article.

\section{Competing Interests Statement}

The authors declared no potential conflicts of interest with respect to the research, authorship, and/or publication of this article.

\section{References}

Abanobi, O. C. (2014). Diabetes Mellitus: Related diseases and risk factors (2nd ed.) Owerri: Onii Publishing House and Abanaheart Publications.

Abanobi, O. C., \& Ewuzie, M. A. (2000). Health and illness: A behavioral approach. Owerri: Mantle Publishers 
Nig.

Al-Hajje, A., Awada, S., Rachidi, S., Zein, S., Bawab, W., El-Hajj, Z., Bou Zeid, M., Yassine, M., \& Salameh, P. (2015). Factors affecting medication adherence in Lebanese patients with chronic diseases. Pharmacy Practice, 13(3), 590-599. https://doi.org/10.18549/PharmPract.2015.03.590

Biraguma, J., Mutimura, E., \& Frantz, J. M. (2019). Knowledge about modifiable risk factors for non-communicable diseases adults living with HIV in Rwanda. African Health Sciences, 19(4), 3181-3189.

British Medical Association. (2002). Illustrated medical dictionary. London: A Penguin Company.

Desai, G., Kandavel, T., \& Chaturvedi, S. K. (2019). Patterns of illness behaviors and its correlates in patients with chronic non-organic pain. Journal of Neurosciences in Rural Practice, 10(1), 60-65. https://doi.org/10.4103/jnrp.jnrp_199_18

Dulla, D., Daka, D., \& Wakgari, N. (2017). Antenatal care utilization and its associated factors among pregnant women in Boricha District, Southern Ethiopia. Diversity and Equality in Health and Care, 14(2), 76-84. https://doi.org/10.21767/2049-5471.100096

Erinosho, O. A. (1979). An aspect of illness behavior in Northern Nigeria and its implications. Nigerian Medical Journal, 9(2), 239-242.

Federal Medical Centre. (2020, February 20). Statistics of chronically ill-patients. Abakaliki: Records Units.

Federal Ministry of Health. (2019). The national health policy and strategy to achieve health for all Nigerians. Abuja: Federal Ministry of Health.

Fong, E., Bargman, J. M., \& Chan, C. T. (2007). Cross-sectional comparison of quality of life and illness intrusiveness in patients who are treated with nocturnal home hemodialysis versus peritoneal dialysis. Clinical Journal of American Society of Nephrology, 10(2), 1195-1200. https://doi.org/10.2215/CJN.02260507

Gheorghe, A., Griffiths, U., Murphy, A., Legido-Quigley, H., Lamptey, P., \& Perel, P. (2018). The economic burden of cardiovascular disease and hypertension in low- and middle-income countries: A systematic review. BMC Public Health, 18, 975. https://doi.org/10.1186/s12889-018-5806-x

Levin, B. L., \& Hanson, A. (2020). Population-based behavioral health. In B.L. Levin \& A. Hanson (Eds.), Foundations of behavioral health (pp. 1-14). Switzerland: Springer Nature. https://doi.org/10.1007/978-3-030-18435-3_1

Musinguzi, G., Anthierens, S., Nuwaha, F., Geertruyden, J. V., Wanyenze, R. K., \& Bastiaens, H. (2018). Factors influencing compliance and health seeking behavior for hypertension in Mukono and Buikwe in Uganda: A Qualitative Study. International Journal of Hypertension. https://doi.org/10.1155/2018/8307591

Nugent, R. (2008). Chronic diseases in developing countries: Health and economic burdens. Annals of the New York Academy of Sciences, 1136, 70-79. https://doi.org/10.1196/annals.1425.027

Nwafor, J. N. (2011). Illness behavior of patients with selected chronic diseases at the federal medical centre, Abakaliki. Unpublished MSc. Ed Dissertation, Ebonyi State University, Abakaliki.

Ogbazi, J. N., \& Okpala, J. (2014). Writing research report: Guide for researchers in education, the social sciences and the humanities (2nd ed.). Enugu: Press Time Ltd.

Petersen, S., van den Berg, R. A., Janssens, T., \& Van den Bergh, O. (2010) Illness and symptom perception: A theoretical approach towards an integrative measurement model. Clinical Psychology Review, 31, 428-439. https://doi.org/10.1016/j.cpr.2010.11.002

Reiners, F., Sturm, J., Lisette J. W., Bouw, L. J. W., Eveline, J. M., \& Wouters, E. J. M. (2019). Socio-demographic factors influencing the use of e-health in people with chronic diseases. International Journal of Environmental Research and Public Health, 16, 645-657. https://doi.org/10.3390/ijerph16040645

Riegel, B., Jaarsma, T., \& Strömberg, A. (2012). A middle-range theory of self-care of chronic illness. Advances in Nursing Science, 35(3), 194-204. https://doi.org/10.1097/ANS.0b013e318261b1ba

Serap, T., \& Bayram, S. (2015). Factors influencing adherence to diabetes medication in Turkey. Scholars Journal of Applied Medical Sciences, 3(2A), 602-607.

Settumba, S. N., Sweeney, S., Seeley, J., Biraro, S., Mutungi, G., Munderi, P., Grosskurth, H., \& Vassall, A. 
(2015). The health system burden of chronic disease care: An estimation of provider costs of selected chronic diseases in Uganda. Tropical Medicine and International Health, 20, 781-790. https://doi.org/10.1111/tmi.12487

Sidhu, M. S. (2012). Understanding health beliefs in relation to chronic disease and self-management in a socio-economically disadvantaged multi-ethnic population. Unpublished $\mathrm{PhD}$ Thesis, University of Birmingham, Birmingham.

Talboom-Kamp, E.P.W.A., Verdijk, N.A., Kasteleyn, M.J., Numans, M.E., \& Chavannes, N.H. (2018). From chronic disease management to person-centered eHealth; A review on the necessity for blended care. Clinical e-Health, 1, 3-7. https://doi.org/10.1016/j.ceh.2018.01.001

Tipping, S. A., \& Segall, C. (2014). Situational obstacles to diction adherence for adolescents with diabetes. Diabetes Education, 20, 207-211. https://doi.org/10.1177/014572179402000305

Uchendu, O. C., Ilesanmi, O. S., \& Olumide, A. E. (2013). Factors influencing the choice of health care providing facility among workers in a local government secretariat in South western Nigeria. Annals of Ibadan Postgraduate Medicine, 11(2), 87-97.

United Nations, Department of Economic and Social Affairs. (2015). World population prospects: The 2015 revision, key findings and advance tables. New York: United Nations, Department of Economic and Social Affairs.

Uzama, J., Underwood, A.C., Atkinson R., \& Thackrah, A. A. (2012). The patient reactions assessment: a brief measure of the quality of patient provider medical relationship. Psychological Assessment, 4, 346-351. https://doi.org/10.1037/1040-3590.4.3.346

Woods, D. W. (2003). Towards developing a theory of spirituality. Journal of Nursing Scholarship, 24, 267-272.

World Health Organization. (2018a). Non-communicable diseases (NCDs) and mental health challenges and solutions. Retrieved April 29, 2020, from https://www.who.int/beat-ncds/en/

World Health Organization. (2018b). Non-communicable diseases. Retrieved April 29, 2020, from https://www.who.int/news-room/fact-sheets/detail/noncommunicable-diseases

Zhu, Z., Liu, Y., Che, X., \& Chen, X. (2018). Moderating factors influencing adoption of a mobile chronic disease management system in China. Informatics for Health and Social Care, 43(1), 22-41. https://doi.org/10.1080/17538157.2016.1255631

\section{Copyrights}

Copyright for this article is retained by the author(s), with first publication rights granted to the journal.

This is an open-access article distributed under the terms and conditions of the Creative Commons Attribution license (http://creativecommons.org/licenses/by/4.0/). 